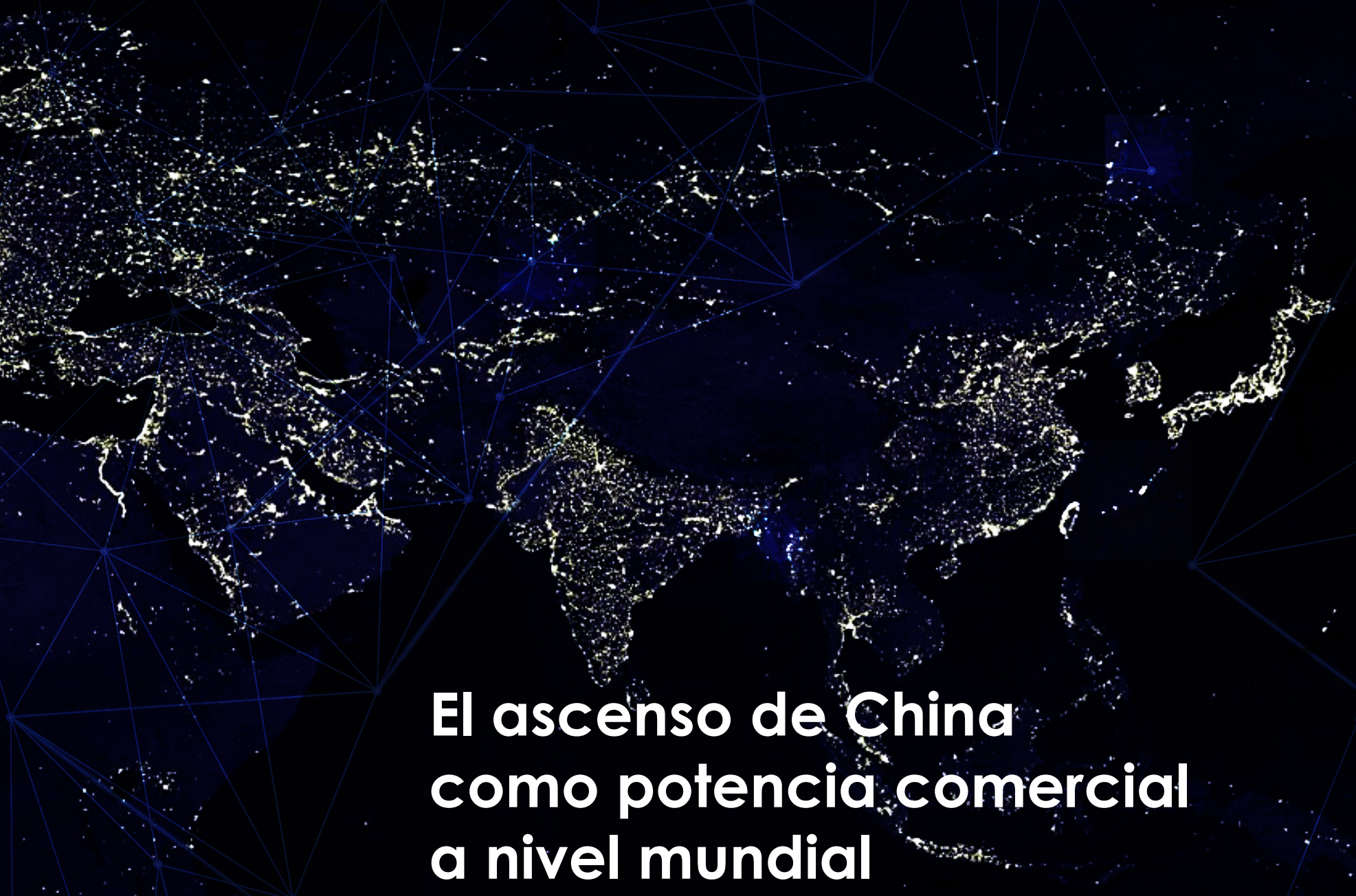

ift

+. 


\section{El ascenso de China como potencia comercial a nivel mundial}

Investigadora: Iria Briceño Álvarez

\section{Resumen}

El objetivo de este artículo es analizar la evolución económica de la República Popular China a través de su desarrollo en la producción y exportación de productos que lo están llevando a convertirse en la nueva potencia comercial mundial, para lo cual primeramente se muestra un estudio dividido en diferentes apartados: el crecimiento económico de China, la capacidad científica y tecnológica que se está desarrollando por medio de la obtención de títulos universitarios por grandes cantidades de su población; y las estrategias comerciales que ha puesto en práctica este gobierno. Asimismo, se abarca el tema de la manufactura de productos falsos y como China ha irrespetado los derechos de marcas. Se presenta, además, la Ruta de la Seda como parte del análisis para ver a China como una nueva potencia comercial mundial, con factores en contra y a favor, así como los retos para que esto se lleve a cabo.

\section{Palabras clave}

China / Desarrollo económico mundial / Comercio internacional / Crecimiento económico

\section{Abstract}

The objective of this article is to analyze the economic evolution of the People's Republic of China through its development in the production and export of products that are leading it to become the new world commercial power, for which first a study divided into different sections is shown: China's economic growth, the scientific and technological capacity that is being developed through the obtaining of university degrees by large amounts of its population; and the commercial strategies that this government has put into practice. It also covers the manufacturing of counterfeit products and how China has disrespected trademark rights. The silk road being built by the Chinese government with the support of other countries is also presented as part of the analysis to see China as a new world commercial power, with factors against and in favor, as well as the challenges for this to take place.

\section{Key words}

China / World Economic Development / International Trade / Economic Growth

Recibido: 25 de marzo de 2021

Aceptado: 18 de mayo de 2021

DOl: https://doi.org/10.35485/rcap80_4 


\section{Introducción}

Después de que finalizara la II Guerra Mundial (1945) Estados Unidos y la Unión Soviética se establecieron como las dos potencias mundiales. A partir de 1989, lvego de la Guerra Fría, Estados Unidos se constituye como la súper potencia mundial en materia económica y militar.

Por su lado, desde el 1978 la República Popular China viene creciendo económicamente, momento en que Deng Xiaoping cambia las políticas estatales, reforma la industria y genera una reforma universitaria en 1979 para lograr avanzar en el desarrollo científico y tecnológico del país. China ha estado cambiando globalmente con grandes transformaciones geopolíticas y debido a su capacidad demográfica ha dado lugar a un crecimiento económico sostenible.

Este artículo pretende analizar la evolución económica de la República Popular China a través de su desarrollo en la producción y exportación de productos que lo están llevando a convertirse en la nueva potencia comercial mundial.

\subsection{Crecimiento económico de la República Popular China}

La República Popular China ha venido presentando un vertiginoso crecimiento en el área económica desde 1980. Luego de que finalizara la Guerra Fría y hasta la actualidad, Hong Kong ha sido un pilar imprescindible para que se diera un rejuvenecimiento en la economía, desde ahí Deng Xiaoping, tuvo acceso a trabajar con moneda extranjera y con esto importar diversos productos, incluyendo alta tecnología, y utilizar como una ventaja a su favor la fuerza de trabajo cualificada de Hong Kong, así como sus directivos profesionales. Así mismo, China también tomó cierta ventaja de Taiwán en aspectos como inversión de capital y en el aspecto tecnológico, utilizándolo para acrecentar su proceso de exportación de productos tecnológicos.

En esos mismos años 80, en el área agrícola China dominó en la producción de cereales, arroz, algodón, papa y té, así como en la cría de ganado ovino y porcino y la producción pesquera, representando el $7,1 \%$ de su producto interno bruto (PIB). En esa década, el gobierno asiático creó alrededor de 300 millones de empleos logrando movilizar gran parte de la fuerza laboral que trabajaba en el campo hacia las grandes ciudades, con la finalidad de que trabajaran en las fábricas, utilizando grandes fuerzas laborales por salarios bajos.

A partir de ahí, fue mejorando su infraestructura industrial y apostando por el comercio con otros países empezando con Asia para continuar con América Latina, África y posteriormente con Europa. En el gráfico que se presenta a continuación se puede observar cómo ha ido creciendo la actividad comercial entre China y Europa del Este entre los años 2009 al 2014.

\section{Gráfico 1. Actividad comercial entre China y Europa del Este: 2009-2014}

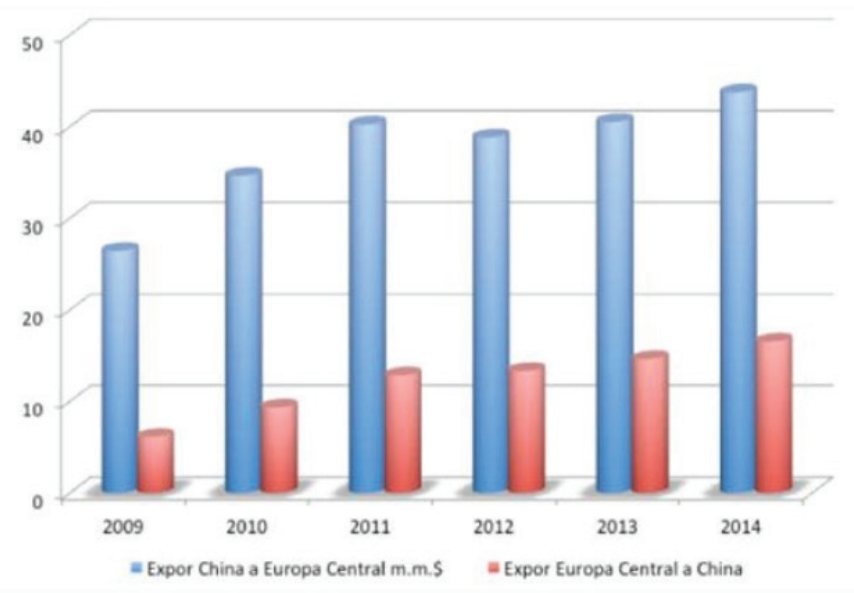

Fuente: Diaz, C. (2017, p.1)

Según lo presenta Shenkar (2005), China logra que se produzca a gran escala y con mano de obra barata, "sus fábricas producen el $70 \%$ de los juguetes del mundo, el 60\% de las bicicletas, la mitad de los zapatos y una tercera parte de las valijas." (p. 3) y es de esta manera como la industria llega a representar el 40,6\% del PIB. El gobierno chino les da mayor libertad a las empresas para que produzcan, pero siempre manteniendo el control total de lo relacionado con la economía en general y además fue aceptado en el año 2001 en la Organización Mundial del Comercio.

A partir del 2010, China presenta un aumento anual aproximado de un $10 \%$ en su crecimiento 
económico, lo consigue pese a todos los pronósticos y a la recomendación que le dan países como Estados Unidos de llevar a cabo una apertura comercial global, esto ha llevado a China a proponer otra estrategia, primeramente, inicia sus contactos comerciales con Europa a través de la Ruta de la Seda y pasa de ser un país meramente agrícola a un país, que, a pesar de ser comunista, abre sus puertas al comercio internacional.

Por otro lado, se activa el sector privado de tal forma que en el año 2015, este representó el $70 \%$ del producto interno bruto de China. En la siguiente tabla se puede observar los indicadores de crecimiento desde el año 2018 junto a una proyección hasta el año 2022, lo que contrasta con la pobreza presente en cierto sector del país asiático, especialmente en la zona rural del país. el año $92 \mathrm{dC}$ por Cai Lun (61 dC - $121 \mathrm{dC}$ ) quien recolectó las cortezas de los árboles junto con cáñamo, trapos rotos y redes de pesca para lograr el medio por el cual se conserva mucha de la historia del mundo.

Entre el año 650 y 670 lograron la impresión por medio de sellos de madera, de una sola hoja escrita en sánscrito (Lengua indoeuropea utilizada en textos sagrados y de culto escritos entre los siglos $X V$ y $X$ ), este documento se imprimió sobre una hoja de papel de cáñamo.

Otro de los grandes descubrimientos de la civilización china fue la pólvora, descubierto entre los años 618 a 907 . En un principio utilizaron la mezcla de azufre, salitre y carbón vegetal que lo obtenían de los sauces. Este proceso se tornaba bastante peligroso porque había un alto riesgo de que se produjera un

\section{Tabla 1. Indicadores de Crecimiento: 2018-2022}

\begin{tabular}{|c|c|c|c|c|c|}
\hline Indicadores de crecimiento & 2018 & 2019 & $2020(e)$ & $2021(\mathrm{e})$ & $2022(\mathrm{e})$ \\
\hline PIB (miles de millones de USD) & 13,00 & $14,00 \mathrm{e}$ & 15,00 & 16,00 & 18,00 \\
\hline PIB (crecimiento anual en \%, precio constante) & 6,8 & $6,1 e$ & 1,9 & 8,1 & 5,6 \\
\hline PIB per cápita (USD) & $9 e$ & $10 \mathrm{e}$ & 10 & 11 & 12 \\
\hline Saldo de la hacienda pública (en \% del PIB) & $-4,5$ & $-5,9$ & $-10,2$ & $-10,9$ & $-10,3$ \\
\hline Endeudamiento del Estado (en \% del PIB) & 48,8 & 52,6 & 61,7 & 66,5 & 71,2 \\
\hline Tasa de inflación (\%) & 2,1 & $2,9 e$ & 2,9 & 2,7 & 2,6 \\
\hline Tasa de paro (\% de la población activa) & 3,8 & $3,6 \mathrm{e}$ & 3,8 & 3,6 & 3,6 \\
\hline Balanza de transacciones corrientes (miles de millones de USD) & 25,50 & 141,34 & 193,42 & 111,66 & 114,24 \\
\hline Balanza de transacciones corrientes (en \% del PIB) & 0,2 & 1,0 & 1,3 & 0,7 & 0,6 \\
\hline
\end{tabular}

Fuente: IMF - World Economic Outlook Database, Octubre 2020

Nota 1: e) Datos estimados

Note 2: The GDP growth projections for 2021 and 2022 (Constant Prices, Annual \% Change) were updated by the IMF in January 2021

Fuente: Fondo Monetario Internacional citado por Banco Santander (2021)

\subsection{Capacidad científica y tecnológica de la República Popular China}

Al crecimiento económico se le suma el desarrollo tecnológico, China fue pionera, a nivel mundial, con sus descubrimientos en ciencia y tecnología desde hace muchos años en la historia de la humanidad. Uno de los grandes logros fue la fabricación del papel en incendio. Este material inflamable fue exclusivo hasta el siglo XIII en que se introdujo en la ruta de comercio de la seda y se traslada a Europa y al Islam, de ahí que se empiece a utilizar en diferentes guerras, como por ejemplo la Guerra de los Cien Años. Hoy en día, todavía hay armas de fuego que lo utilizan. 
La brújula igualmente fue un invento chino, elaborada en sus inicios con hierro (metal descubierto también por este país asiático) y magnetita. Este artefacto se utilizó primeramente en tierra debido a las grandes extensiones terrestres en Asia. De China pasó a la India, al mundo musulmán y luego a Europa, donde se modificó y se le dio mayor uso al igual que al papel, la pólvora y la imprenta.

Debido a que la producción de insumos como juguetes, zapatos, entre otros, vino en declive en los últimos años, el gobierno chino vuelve de nuevo sus ojos hacia el campo científico y tecnológico, de tal manera que ya se está hablando, por parte del resto de países, de que esta situación se puede convertir en el nuevo motor económico de este país asiático.

China ha sido capaz de realizar un giro en sus políticas para favorecer la innovación en la producción científica y tecnológica del país, como medio para incorporarlo en la industria de nuevas tecnologías y que favorezca a su crecimiento económico.

Inició con la producción de electrodomésticos como hornos de microondas, televisores, lavadores, refrigeradoras, entre otros hasta llegar a la producción de nuevas tecnologías, tales como celulares y computadoras junto a sus implementos, entre otros.

\section{Estrategias comerciales de la República Popular China}

Para el año 2009, el impacto provocado por la recesión mundial también golpeó al gigante asiático, China empieza a tener problemas con las exportaciones, algunas empresas deben de cerrar porque no tienen a quien venderle sus productos y miles de personas pierden su empleo, además se enfrentan a un problema sociales debido a que su población está cada vez más envejecida y hay menos nacimientos como se puede ver en las proyecciones de la siguiente tabla:

Esta situación agrava el problema económico debido a que por la edad de la población impacta en diversos espacios sociales, por ejemplo, se debe de contemplar los montos de pensiones.
Debido a estos factores, el gobierno chino empieza a de buscar la manera de cambiar, una vez más, su estrategia comercial, por lo que "China ha iniciado aproximadamente hace ocho años un nuevo enfoque de su desarrollo, el desarrollo hacia adentro" (Burgos y Villegas, 2018, p. 3), es decir, empezar a preocuparse de su mercado interno, la población china es un gran cliente potencial y socialmente hablando también estaban deseosos de poder adquirir bienes y servicios de calidad, por lo que empiezan a invertir en la economía interna.

Al mismo tiempo, el país asiático inicia una campaña de promoción a nivel mundial, de tal forma que ha generado espacios de cooperación en muchos países, principalmente financiado infraestructuras importantes en países como Camboya, Sudáfrica o Costa Rica, donde donó la construcción del Estadio Nacional en el año 2008, obra que se finalizó su construcción en diciembre del 2010 y fue entregada por el gobierno de China el 10 de enero del 2011.

Esta política es de utilidad para que lograr entablar alianzas diplomáticas con diversos países, por eso para el año 2018 se consolida la creación de la Agencia de Cooperación para el Desarrollo Internacional de China, que sirve para dictar "las directrices y políticas estratégicas sobre ayuda exterior; y que coordinará y hará sugerencias sobre importantes asuntos relacionados; reformará el sistema de ayuda exterior, y elaborará planes

Tabla 2. Evolución y previsión de la estructura de edades y de la tasa de dependencia

\begin{tabular}{lccccc} 
Cuadro 1. Evolución y previsión de la estructura de edades y de la tasa de dependencia \\
\cline { 2 - 6 } & $\begin{array}{l}\text { Población total } \\
\text { (millones) }\end{array}$ & $\begin{array}{l}0-14 \\
(\%)\end{array}$ & $\begin{array}{c}15-64 \\
(\%)\end{array}$ & $\begin{array}{c}65 \text { y más } \\
(\%)\end{array}$ & $\begin{array}{r}\text { Tasa de } \\
\text { dependencia }\end{array}$ \\
\hline 1960 & 667.07 & 39.96 & 56.39 & 3.65 & 6.47 \\
1970 & 818.31 & 40.67 & 55.66 & 3.66 & 6.58 \\
1980 & 981.23 & 36.20 & 59.31 & 4.49 & 7.57 \\
1990 & 1135.18 & 28.84 & 65.82 & 5.34 & 8.11 \\
2000 & 1262.64 & 25.07 & 68.28 & 6.65 & 9.74 \\
2010 & 1337.70 & 17.41 & 74.34 & 8.25 & 11.10 \\
2014 & 1364.27 & 17.20 & 73.61 & 9.18 & 12.47 \\
$2050 *$ & 1348.05 & 13.50 & 58.90 & 27.60 & 46.86 \\
$2100 *$ & 1004.39 & 1340.00 & 52.80 & 33.80 & 64.02 \\
\hline * Escenario intermedio. ** \% Personas mayores de 65 / personos entre 15 y 64 años. \\
Fuente: Indicadores del Desarrollo Mundial. Banco Mundial. World Population Prospects. Revisión de 2015. Banco Mundial.
\end{tabular}

Fuente: Banco Mundial citado por Burgos Chaves, P. y Villegas Sibaja, L. (2018, p. 15) 
y supervisará su implementación." (Xinhua español, 2018, p. 1).

El despegue de la producción industrial en China estuvo caracterizado también por el surgimiento de una práctica generalizada en dicho país, que tiene que ver con la manufactura de productos "falsos", lo que conlleva el irrespeto a los derechos de autor, este tipo de práctica en China se puede rastrear desde algunos siglos atrás cuando Qin Shi Huang, primer emperador de esta nación, que en el siglo III aC, cuando conquistaba un territorio construía una réplica de los palacios dentro de su propia ciudad capital.

Esta práctica se incrementó, en el sector comercial, en el año 1980 cuando se permitió la entrada de empresas privadas a China, y este país, estaba sufriendo una baja en la producción, en ese momento no era factible la inversión en investigación y estudios, por lo que optaron por copiar/duplicar productos, de modo que se apostó por generar mercancía con sus recursos limitados pero personal sin mayor preparación académica, lo que se buscaba era tener un éxito instantáneo.

En este momento, un sector bastante grande de mercado global sirvió como comprador, pues prefieren adquirir copias, sobre todo por la facilidad económica, los artículos son prácticamente iguales pero su valor es mucho más barato que el original, sin embargo, algunos de ellos de muy baja calidad.

Esta situación de infracción de patentes significa una pérdida de millones de dólares y euros para los dueños de esa propiedad intelectual, según la Oficina de Propiedad Intelectual de la Unión Europea (EUIPO), para las empresas europeas les cuesta alrededor de US\$68.000 millones por año. Para el año 2013 esta pérdida fue de 338,000 euros a nivel mundial.

Según un estudio de Falsificaciones del año 2016 elaborado por la OBS Business School (escuela de negocios online) en China se produce el $67 \%$ de materiales falsificados y en Hong Kong un 22,6\%, afectando en mayor grado a países como Estados Unidos, Italia, Francia, Suiza y Japón.
Otra de las críticas que ha recibido esta práctica del país asiático es que utilizan mano de obra infantil, con malas condiciones laborales y salarios muy bajos. Ante esta situación realidad, el gobierno de China asegura que ya inició con la aplicación de medidas para el control de esta práctica, llevando a cabo una campaña que reforme su infraestructura legal sobre los derechos de autor, de patentes y de marcas.

\subsection{China y la ruta de la seda}

China se ha dado a la tarea de construir la "Ruta de la Seda" por medio de pactos económicos con los países centro asiáticos y de Oriente Medio buscando ampliar su hegemonía política en Eurasia, que según el geógrafo inglés Mackinder (1861-1947), es el área más importante, estratégicamente para el dominio del mundo. Para Mackinder el país o potencia que llegue a dominar en Europa del Este, logrará el dominio de Heartland y quien domine el Heartland automáticamente dominará la Isla-Mundo y con esto llegará a controlar el mundo. Por su lado, para Nicholas Spykman (1893-1943) no era necesario controlar el Heartland, ya que se podía lograr el mismo objetivo si se rodeaba.

Según la delimitación del Heartland de Mackinder, China es parte de ésta por sus territorios del noreste, es decir, Sinkiang. Se cree que puede llegar a convertirse en una potencia terrestre debido a su crecimiento que, a partir de 1990, se incrementa en cuanto a su economía, su comercio y política exterior y su gran presupuesto para defensa. Así mismo, China está intentando expandirse económicamente hacia Asia Central debido a sus recursos energéticos y para extender la industria comercial de sus productos. Sin embargo, en Asia Central aún hay pueblos en disputa y en vías de desarrollo, así como en este momento China tiene conflictos con Hong Kong, Taiwán y el Tíbet.

Lo que ha potenciado el enfrentamiento por la hegemonía entre Estados Unidos y China, donde Estados Unidos ejerce como una potencia marítima, con bases en todo el globo terráqueo y China creciendo ampliamente en el área terrestre, con gran influencia en Asia. 


\section{Gráfico 2. Cuentas bancarias gubernamentales: Saldos de la cuenta corriente}

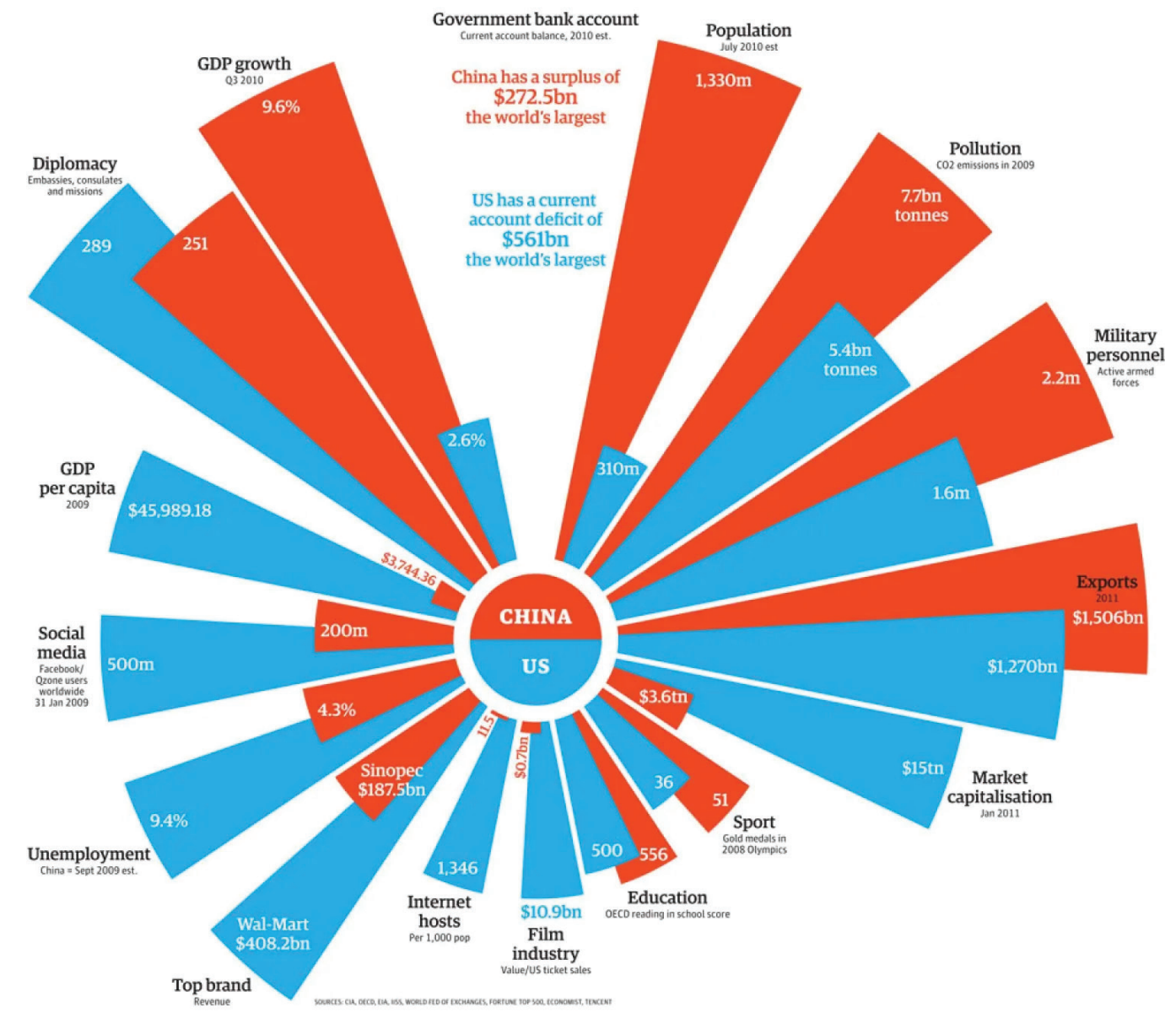

Fuente: Arancón, F. (2013)

El gráfico 2, presenta una comparación entre ambos países en diferentes industrias y procesos de influencia económica.

\section{China como nueva potencia comercial mundial}

A partir de la década de los 80 China pasó de una economía planificada a una economía capitalista, sin abandonar sus raíces políticas comunistas y desde ese momento crecido aceleradamente con respecto a Estados Unidos y el resto del mundo en general.

El gobierno chino, a través de esta reforma comercial pasó a internarse en un sector de privatización y creación de zonas de libre comercio o libre mercado, en donde en muchas ocasiones las leyes nacionales son suspendidas en los límites de esta zona especial. Esto le permitió entrar a jugar en las grandes ligas de la economía mundial.
China inició con un cambio o reforma en el área agrícola, adaptando sus técnicas y organización a condiciones diferentes a las que estaban acostumbrados hasta ese momento.

El país asiático se abrió a la inversión extrajera y permitió que empresas de otros países, entre los que se encontraba Estados Unidos, se instalaran en China para producir sus productos aprovechándose de la contratación de mano de obra barata, es decir, de personas trabajadoras a las cuales no necesitaban pagarles grandes sumas de dinero como salario. Estas compañías tuvieron el permiso del Estado para desarrollar la libre empresa.

Para 1990 habían avanzado a una inversión extranjera directa y con estos cambios comenzó un crecimiento económico a partir, en gran medida, de las exportaciones de maquinaria y equipo de bajo costo. Para este momento, China propiciaba la exportación 
de productos, pero no así la importación de ningún tipo. Esta situación continuó y para principios del año 2000 Estados Unidos y los países del globo importaban y consumían productos chinos.

Para el año 2017, con la toma de poder de Donald Trump se acentúa una "guerra comercial" entre estas dos naciones, donde cada una busca hacerse o mantener la hegemonía económica mundial.

Ahora bien, lo que es destacable es que revisando el comportamiento económico de China se puede observar que para el año 1990, este país asiático no se encontraba entre las diez economías más grandes del mundo, en 1992, logra ingresar a esta selecta lista y ya para el 2010 se colocó en el segundo peldaño, desplazando a Japón, tal y como se puede ver en el siguiente gráfico, elaborado con datos del Banco Mundial.

\section{Gráfico 3. Top 10 de las economías más grandes}

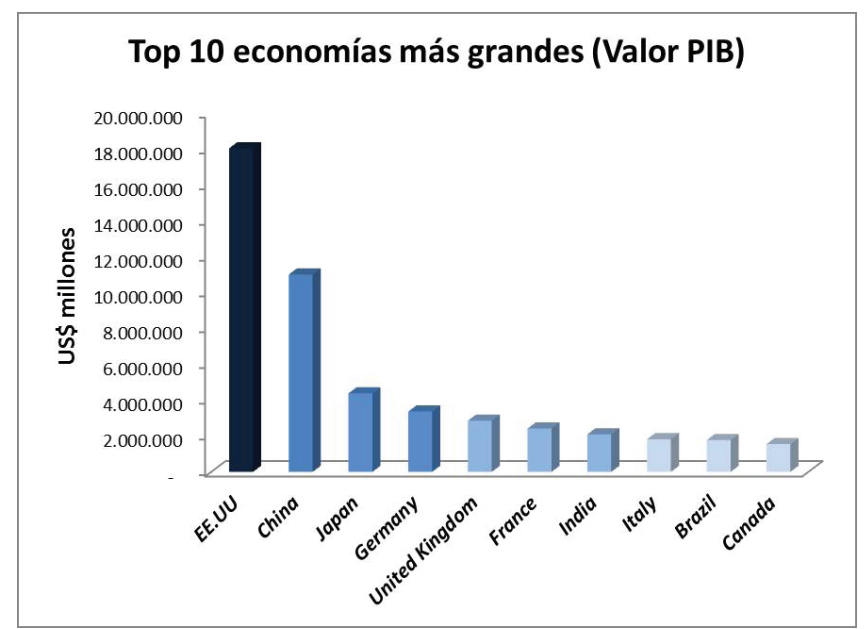

Fuente: Banco Mundial citado por Semana (2017)

En cuanto al desarrollo económico China lleva la delantera puesto que en el periodo que comprenden los años de 1980 al 2010, su tasa de crecimiento ha estado por encima del 8\% en contraposición de Estados Unidos que no lo ha logrado y que inclusive en los últimos años ha tenido tasas negativas en su aumento. Esto en cuanto a la medición del PIB por crecimiento económico.
Cuando se estudia el PIB por la paridad en el poder adquisitivo (PPA), se puede ver el efecto sobre el nivel de vida de estos dos países con respecto a la adquisición de bienes y servicios. De hecho, desde el año 2014 China ha superado a Estados Unidos, para el año 2015 el PPA de China llegó a los 18,3 billones de dólares y el de Estados Unidos llegó a 17,5 billones. Ya para el año 2000 China llegó a 29,7 y Estados Unidos a 22,2 billones de dólares.

Es importante conocer el PIB con respecto al nivel de vida de la población de cada país, es decir, del PIB pér cápita, que para Estados Unidos estaba, en el 2015, en 62,640 dólares en contraposición con el de China que llegó a 18,210 dólares. Esto con datos demográficos de China con 1.400 millones de habitantes y Estados Unidos con 327 millones.

\subsection{Factores en contra para que China se convierta en la súper potencia económica mundial}

\subsubsection{Envejecimiento de su población:}

China tiene una superficie total de 9.562.910 $\mathrm{Km}^{2}$, con lo cual es uno de los países con mayor extensión del mundo. Igualmente, tiene la población más grande del mundo, que oscila entre 1.412.280.450 personas, es decir, aproximadamente 146 habitantes por metro cuadrado. Tenía una tasa de crecimiento para el año 2019 de 0,52\%

Esta densidad de población permitió que China tenga y ofrezca a la inversión extranjera una mano de obra barata, pero que año tras año se vuelve más longeva y con esto crece la población que necesita de otro tipo de beneficios por parte del Estado.

\section{1.2. Disminución de la fuerza laboral:}

Como se expuso en el punto anterior, la población china se vuelve, en forma acelerada, en un pueblo de personas viejas con lo cual se comprime la oferta laboral y, a esto hay que sumarle el hecho de que mucha de la población joven no planea tener hijos. Esto puede traer como consecuencia de que el país ya no sea tan atractivo para la inversión de las compañías extranjeras. 
3. 1.3. Falta de apertura de su sistema político - económico:

Para el año 2020 se puede afirmar que los mercados financieros de China no son transparentes, ni estables ni confiables. Hace falta que China logre desarrollar su mercado financiero, para lo cual necesita hacer reformas de índole económico para lograr que el mercado sea estable y con liquidez, y evitar que este mercado sea tan volátil. Otro punto importante, es que China debe de analizar la apertura a la privatización del sector productivo y no estar tan implicado en la toma de decisiones con respecto a la inversión y al tipo de campo de las divisas. Así como, debe de controlar el respeto a los derechos de autor, patentes y de marca.

\section{1.4. Competitividad económica con alto} grado de capital y expansión del crédito:

El mundo no confía demasiado en la moneda de China, el Yuan. La moneda en la que se pacta, a nivel mundial, es el dólar, a razón de que el $61.7 \%$ de las reservas mundiales se encuentran en dólares y solo el $1.9 \%$ se ubican en Yuanes. Por un lado, el PIB de China es, este momento, el segundo más grande del mundo, sin embargo, cuando se revisa su PIB per cápita, sigue siendo un país de ingresos medios.

\subsection{Factores a favor para que China se convierta en la súper potencia económica mundial}

\subsection{Diferencia entre lo urbano y lo rural, una oportunidad de crecimiento:}

En China, en la actualidad se ha incrementado las diferencias sociales entre su población. Esto se ha traducido en el surgimiento de una clase media y con esto se ha incrementado el poder adquisitivo de este sector. Con esto el gobierno chino logró empezar a vender sus propios productos a lo interno del país, en el momento en que se encrudecía, por factores económicos, las exportaciones. Debido a este crecimiento del sector medio de la población el PIB per cápita chino subió y aportó un poco más del $60 \%$ del crecimiento del Estado.

\subsubsection{Ventajas en los factores de producción}

China tiene la ventaja de poseer gran cantidad de territorio y una abundante cantidad de población, por lo que prácticamente desde la década de los años 90, dividió al país para ser tener una división del trabajo en diferentes partes de la nación:

- Guandong, provincia situada en la costa sureste de China y que limita con Hong Kong y Macao la convirtió en una zona de exportaciones de trabajo intensivo. Esta provincia cuenta para el 2018 con una población de más de 113 millones de personas. En este momento, tiene la economía más grande de China, con un tamaño equivalente para el 2018 de 1,47 billones de dólares (USD). Es una de las zonas de más rápido crecimiento de China en las últimas décadas.

- Zhejiang provincia ubicada al este de China abarca un área rural y centros urbanos a lo largo del Mar de la China Oriental. Esta provincia está orientada a la exportación, pero más de capital extensivo. En el área rural su economía se basa en el área agrícola con cosechas de arroz, algodón y té. En cuanto al área industrial son especialmente químicas, textiles, alimentarías y de materiales para la construcción.

- Alrededor de Pekín, aquí se ha desarrollado su industria de alta tecnología, comunicación y aviación. Esta diversificación es parte de la estrategia a conciencia del estado para desarrollarse como una potencia económica.

\subsubsection{Desarrollo de la ciencia y la tecnología:}

China está formando talento humano dentro y fuera del país. Para el año 2018 ya eran alrededor de 662.000 ciudadanos estudiando en el extranjero, que en el momento en que regresen tendrán un título de maestría o superior. Así mismo, cada año se gradúan de las universidades nacionales alrededor de 8 millones de personas, a diferencia de Estados Unidos que gradúa aproximadamente menos de 4 millones de estudiantes.

De ahí que China se esté convirtiendo en el líder en el área de la ciencia y la tecnología, y va a 
la vanguardia de sectores como la inteligencia artificial, la robótica y las telecomunicaciones, entre otros. China quiere pasar del "Hecho en China" a "Diseñado en China", para lo cual es necesario que continué con el proceso de fomentar la creación de marcas propias, de que sus profesionales empiecen a innovar. Como ejemplo de esto, se puede ver el desarrollo que ha tenido la empresa Huawei, que es proveedor a nivel mundial de tecnología en sus diferentes presentaciones.

\subsubsection{Inversión y sostenimiento en las empresas} estatales:

A pesar de que la rentabilidad de estas organizaciones es menor a las compañías extranjeras, China busca que crezcan y mejoren para fortalecer la industria nacional. Esto puede ayudar a que su Producto Interno Bruto se incremente, en el momento en que se refuercen y puedan brindar sus productos a nivel internacional.

\subsection{Principales retos para que China se convierta en la súper potencia económica mundial:}

Los siguientes son algunos factores que serán claves para la República Popular de China en su camino por consolidar su influencia económica global;

- Favorecer el consumo interno de los productos fabricados y diseñados en China, promoviéndolo a nivel interno.

- Promover la urbanización, ya que por medio de esto tendrán gran demanda en el consumo, así como de inversión en bienes y servicios. Esto a su vez va a favorecer la creación de empleo.

- Procurar que los ciudadanos chinos que migran a la ciudad tengan posibilidades de empleo.

- Brindar un excelente servicio al turista extranjero para promover el ingreso de divisas y con esto favorecer el crecimiento del PIB. Igualmente, favorecerá la generación de empleo entre su población.

- Desarrollo de la industria para que favorezcan y promuevan la exportación a nivel global.

\section{Conclusiones}

El caso de China es importante de estudiar por parte del resto de países del mundo, ya que pasó de ser una nación en decadencia a estar a punto de lograr sobrepasar a Estados Unidos a nivel económico. Su crecimiento es el resultado de una combinación de factores que van desde su reorientación en la producción nacional, así como el entrar en ciertos factores económicos dentro del capitalismo global en la década de 1980.

En este momento, se habla de que este país asiático está a punto de convertirse en una súper potencia mundial a nivel económico, pero no necesariamente a ser un líder sobre todo por su falta de fidelidad y por no respetar los derechos de autor y de marca. El gobierno chino ha estado muy preocupado y ha trabajado arduamente para modernizar su economía y sus relaciones diplomáticas mundiales, esto debido primeramente a razones de su defensa como nación y lograr no ser invadido ni colonizado como cien años atrás. Segundo, por razones ofensivas, ya que busca volver a tener su estatus como gran potencia.

China a través de todas estas adecuaciones y transformaciones ha ido consolidando su crecimiento en materia económica. Sin embargo, debe de prestar atención a situaciones como el caso de la empresa Huawei, que en este momento se puede decir que se ha posesionado como una marca mundial, pero que para su desarrollo contrató a científicos chinos, pero también japoneses.

Igualmente, China ha estado apostando con iniciar relaciones diplomáticas con los países de América Latina, por medio de las exportaciones de productos y las ayudadas que les ha brindado. Según Perrotti (2015, p. 49) "Para América Latina, China representa un socio estratégico. El comercio bilateral entre ambas ha crecido cuantiosamente a lo largo de la primera década del siglo XXI, alcanzando los 120.000 millones de dólares durante el año 2009." 


\section{Referencias bibliográficas}

Arancón, F. (2013) Teoría del heartland: la conquista del mundo. Recuperado de https://elordenmundial.com/teoriaheartland-conquista-del-mundo/

Banco Santander (2021) China: política y economía. Recuperado de https://santandertrade.com/es/ portal/analizar-mercados/china/ politica-y-economia? url_de_la_ page $=\% 2 \mathrm{Fes} \% 2 \mathrm{Fportal \%} 2 \mathrm{Fanalizar}-$ mercados\%2Fchina\%2Fpoliticay-economia\&\&actualiser_id_ banque=ovi\&id_banque $=0 \&$ memoriser_ choix=memoriser

Burgos Chaves, P. y Villegas Sibaja, L. (2018) República Popular China: El cambio de estrategia comercial hacia adentro. Costa Rica: Universidad de Costa Rica.

Diaz, C. (2017) China ¿̇el nuevo líder económico mundial? Crónica mundial (diciembre), p. 1-2. Recuperado de https://cronicaglobal.elespanol.com/ pensamiento/china-lider-economicomundial_107012_102.html

Linde García, R. (2018) La estrategia de China en el nuevo orden económico mundial. Boletín económico de Información Comercial española. No. 3097, p. 23-36 Recuperado de http://www.revistasice. com/index.php/BICE/issue/view/597/ PDF\%20BICE\%203097

Morris, R. (2016) La fascinación de los chinos por los productos falsos: algo más que un gran negocio. BBC Mundo (2016, 22 de diciembre). Recuperado de https:// www.bbc.com/mundo/noticias-38406955

Pérez Saiz, S. (2018) La economía y finanzas chinas y nuestras relaciones económicas y comerciales. Boletín económico de Información Comercial española. No. 3097, p. 11-22. Recuperado de http:// www.revistasice.com/index.php/BICE/ issue/view/597/PDF\%20BICE\%203097
Perrotti, D. (2015) La República Popular de China y América Latina: impacto del crecimiento económico chino en las exportaciones latinoamericanas. Revista Cepal, 116 (agosto), p. 47-60

Santiso. J. (2006) ¿ Realismo mágico? China e India en América Latina y Africa. Economía exterior. No. 38 (Otoño), p. 59-69

Semana (2017) Las economías más grandes del mundo ¿̇cómo se distribuye el PIB a nivel global? Recuperado de https:// www.semana.com/economia/articulo/ economias-mas-grandes-del-mundo-portamano-del-pib/243710/

Shenkar, O. (2005) El siglo de China: la floreciente economía de China y su impacto en la economía global, en el equilibrio del poder y en los empleos. Colombia: Norma

Xinhua español (19 abril 2018) China inaugura Agencia de Cooperación para el Desarrollo Internacional. Xinhua español. Recuperado de http://spanish.xinhuanet. com/2018-04/19/c_137120713.htm 